\title{
Compensation for medical misadventure and drug injury in the New Zealand no-fault system: feeling the way
}

\author{
RICHARD SMITH
}

Legislators all round the globe are having problems in finding just and efficient systems for compensating people injured by medical misadventure and drugs. The medical malpractice problems of the United States are notorious, and in that country there are just as many difficulties with compensating people allegedly injured by drugs. ${ }^{1-3}$ In Britain the Pearson Commission reported five years ago on the problems of compensation for personal injury, ${ }^{4}$ yet its recommendations have never been seriously debated. ${ }^{5}$ There has been no great increase in the numbers of cases of medical negligence, but there have been whispers of unhappiness with the system. ${ }^{6}$ For compensation for injury by defective products (which would include drugs) the Pearson Commission recommended a system of strict liability, whereby the plaintiff would not have to prove fault on the part of the defendant, ${ }^{4}$ and such a law is now being fashioned in Europe. But several commentators have criticised this proposed scheme,$^{8-10}$ and American experience with strict liability does not suggest that it will lead to justice and efficiency. ${ }^{2}$

Many people believe that real progress towards justice and efficiency in compensation could be made by the introduction of a no-fault system, whereby injured people were compensated by a central fund without having to resort to the courts. ${ }^{35}$ Such a system exists in New Zealand for compensation for "personal injury by accident"; I have discussed the general aspects of the system in articles published in the last few weeks (24 April, p 1243; 1 May, p 1317). Some cases of medical misadventure and drug injury are covered by this scheme. This article examines more closely how the New Zealand system compensates these two categories of injury.

\section{Medical misadventure}

Some New Zealand doctors think mistakenly that actions through common law for medical negligence are finished. All New Zealand doctors still have to subscribe to the defence societies, but it is widely thought that the Accident Compensation Corporation will cover all cases where negligence might be alleged. The Accident Compensation Corporation has recently warned all doctors that this is not so, 11 but which cases will be compensated by the Accident Compensation Corporation, and which will need to be fought out in the courts, is not entirely clear. ${ }^{12}$ What is clear is that if a claim is accepted by the Accident Compensation Corporation then it is not possible to make a claim through the courts.

The Accident Compensation Act specifically states that "personal injury by accident" includes "medical, surgical,

British Medical Journal, London WC1H 9JR

RICHARD SMITH, BSC, MB, assistant editor dental, or first aid misadventure." What exactly constitutes medical misadventure is slowly being worked out as cases arise and the scheme develops (it started only in 1974), but the Accident Compensation Corporation is quite definite that: "It is not necessary to show that there has been negligence on the part of a medical practitioner before a claim will lie for medical misadventure." 11 But the Corporation states also that: "Not all cases of medical negligence come within the scope of medical misadventure. While acts of operational negligence will obviously be included, an act of omission in failing to respond to a call for treatment would not be included." 11

One of the earliest cases that showed the limits of Accident Compensation Corporation cover was that of $\mathrm{Mr}$ Collier. ${ }^{13} \mathrm{He}$ entered hospital in 1974 with a history of abdominal pain, diarrhoea, and vomiting for a few days. He was admitted in the morning and the same afternoon underwent a laparotomy at which his appendix was removed. The next morning he died, and the necropsy showed that three feet of his small bowel were infarcted. The Accident Compensation Corporation declined to compensate his widow on the grounds that the death had resulted from disease and not from anything that the doctor had done; the failure to diagnose was not deemed to be medical misadventure. A common law case alleging negligence might well, however, have succeeded.

Another important case arose in 1974, and the conclusions reached and published by the Accident Compensation Corporation in 1978 provided a working definition of what was and what was not medical misadventure. ${ }^{14} \mathrm{Mr} \mathrm{E}$ had been ill for about five days with abdominal pain and vomiting. He went to see his GP on 5 September 1974 and was prescribed some pills and sent home. The next day his condition worsened, and his wife tried to obtain medical help but was unsuccessful. The day after that she called the duty doctor, who came and arranged admission to hospital, but $\mathrm{Mr} \mathrm{E}$ died before the ambulance arrived. Necropsy showed the cause of death to be bilateral lobar pneumonia.

The Accident Compensation Corporation turned down the claim, and in his report the Commission's delegate wrote ${ }^{14}$ :

Medical misadventure occurs when:

(a) a person suffers bodily or mental injury or damage in the course of, and as part of, the administering to that person of medical aid, care or attention, and

(b) such injury or damage is caused by mischance or accident, unexpected and undesigned, in the nature of medical error or medical mishap.

The non-availability of medical assistance is not a situation related to medical treatment of a patient, or to the actual delivery of such treatment. The deceased had not therefore suffered medical misadventure, and the Commission's decision declining the claim was correct.

Alternatively the application failed because the deceased did not die as a result of personal injury by accident: the events relating to the seeking of medical aid were no more than accompanying circumstances, and not accidents or an accident.

The application failed also on the ground of causation. The events 
in question did not positively cause, or contribute, to the deceased's death.

I heard while in New Zealand that this case was subsequently settled out of court after a negligence claim had been made.

Another crucial case, to which the officers of the Accident Compensation Corporation pay a lot of attention, arose in $1976 .^{15}$ Mrs M, who had four children, was admitted to hospital for a laparoscopic sterilisation. During the operation the gynaecologist experienced a few difficulties with the forceps. Mrs M later conceived.

In this case the Appeal Authority held that:

"1. Medical mishap, which is one of the two headings of medical misadventure, may occur where there are adverse consequences of proper treatment but those consequences must be beyond the range of normally and reasonably contemplated risk, before entitlement can arise.

2. Applying this definition, two factors were decisive in determining that medical mishap had occurred in this case:

(i) The forceps "problem" in the operation itself which was not within the normal contemplated risks of such an operation and

(ii) The patient's complete unawareness of any risk of failure in the operation and of possible subsequent pregnancy.

3. Accordingly, on the special facts of the case, the appellant had suffered medical misadventure. The totality of the sequence of events established a causation between the failure of the operation and the injury. (The unwanted pregnancy.) The appeal was therefore allowed."

Other cases of failure of sterilisation have been declined by the Accident Compensation Corporation on the grounds that failure was well recognised to occur in some cases. The problems with the forceps and the fact that she had no idea that failure was a possibility were the crucial factors in Mrs M's case. This second factor, that Mrs $M$ did not fully understand the risks of the procedure, raises the question of "informed consent." No cases have yet arisen in New Zealand, where the Accident Compensation Corporation has compensated somebody on the basis simply that they had not given "informed consent." Whether the Accident Compensation Corporation, or even the courts, would compensate somebody on such a basis is not yet clear. ${ }^{12}$

Everybody that I spoke to in New Zealand, including doctors, lawyers, and members of the Accident Compensation Corporation, agreed that the definition of medical misadventure is broadening. Some of the recent cases that I heard about seem to confirm this. One case, for instance, was of a woman with pernicious anaemia and menorrhagia who had a hysterectomy. She bled postoperatively and was initially treated conservatively with blood transfusions. Eventually she had an operation, and the bleeding was stopped, but she developed renal failure and needed to be dialysed. A shunt was put in and she was heparinised. Soon after this she suffered an intracerebral bleed. This case was accepted by the Accident Compensation Corporation, and it seemed to be influenced by the catastrophic outcome.

Another recent case was of a young sailor admitted to a naval hospital with back pain. He had problems moving his legs but this was thought by the junior doctor to be an hysterical conversion reaction. He was left over the weekend and by Monday morning was paraplegic: he had an epidural abscess. He was compensated quickly, and again the severity of the outcome prevented arguments as to whether this was an error of omission or commission.

Few of the Accident Compensation Corporation cases get as far as the high courts, and the whole process, even that of appeal, is much less formal and rigorous than a legal hearing. There is lots of room for "fudging," which in many ways allows compensation of cases where the outcome is catastrophic and very unexpected even if by the strictest criteria they might not be eligible for compensation. The system has a human face.

\section{Maintaining standards}

In a common law system people may sue doctors not only to gain compensation but also "to see justice done" and a "wrongdoer reprimanded." The Accident Compensation Corporation is not concerned with allotting blame, and some New Zealand doctors, including the Dean of the Auckland Medical School, are concerned that there may thus be a decline in standards in New Zealand medicine. One of the ironies of the no-fault system is that in many ways the grosser the error the more likely the Accident Compensation Corporation is to compensate the victim and the less likely the doctor to be involved in any dispute. I heard of one case that illustrates this problem.

A woman was admitted to hospital for investigation of infertility and was due to have a dilatation and curettage. Instead, she had her Fallopian tubes treated with diathermy. Her case was accepted by the Accident Compensation Corporation, and it paid for her to go to Sydney for reconstructive surgery, which failed. There was an appeal over the amount of compensation she received, and in the hearing the judge mentioned that he thought that there had been negligence in this case.

The remarkable thing is that it is quite possible that the doctor who did the operation does not know that hearings have been taking place. The case was so "open and shut" that the doctor would not be required to give evidence. This absence of "feedback" worries some doctors, and a mechanism is being established for referring such cases from the Accident Compensation Corporation to the Medical Practitioners' Disciplinary Committee. This committee is hearing more and more cases brought by people who are primarily interested in having their grievances aired rather than in gaining compensation.

\section{Compensation for drug injury}

Drug injury is seen in many cases as one form of medical misadventure. Some drug injuries are compensated by the Accident Compensation Corporation, but the number of cases has been small and the criteria for deciding which cases are compensated are far from clear. The Accident Compensation Corporation has, in fact, decided that this is a problem that requires greater investigation, and it is reviewing all the cases (some 50 to 100) that have been compensated. (It has no organised records of the probably much greater number that have been declined.) The New Zealand Adverse Drug Reactions Committee is also concerned about the problem: it thinks that not enough druginjured people are compensated and has asked the Accident Compensation Corporation to consider the matter further. A member of the Accident Compensation Corporation now sits on the Adverse Drug Reactions Committee, but few developments have happened so far.

I repeatedly asked people from the Accident Compensation Corporation what were the criteria for deciding whether a person with a drug reaction would be compensated. The most important criteria seem to be the severity of the reaction and how unexpected it was. When considering rarity, however, there is a catch: supposedly, the reaction cannot be so rare that there is any doubt over causation, but it must not be so common as to be a well recognised side effect. Whether the doctor has or has not warned the patient of the possibility of the reaction does not seem to matter much, but the severity does.

Accordingly, several cases of people turned deaf by gentamicin have been compensated, although this is a well known side effect. Whether the doctor monitored blood concentrations seemed to have been important in at least one case, and the patient seemed to have been compensated as a case of medical misadventure on the grounds that the doctors had not been as careful as they should have been in monitoring the serum gentamicin concentrations. Other patients have, however, been compensated without investigating too closely how the drug was used. But if severity is a crucial factor it seems strange that a woman who became blind after treatment with gold and 
azathioprine was turned down by the Accident Compensation Corporation. Most of the decisions are made by claims officers, who usually come from an insurance or accounting background, and doctors and lawyers may not be much involved. Some argued to me that these cases should be considered in much more detail with evidence being taken from doctors who treated the case and from experts on the various problems. The problem with such an approach would be that the running costs of the Accident Compensation Corporation might rise rapidly.

\section{A classic case}

In Britain and Europe a hypothetical case of a woman on the pill who has a stroke is often invoked to illustrate the difficulties of compensating drug injury, and I was intrigued to discover that a case something like this has occurred in New Zealand. Such cases are invoked because they raise so many unanswerable questions: was it the pill that caused the stroke or would she have had one anyway; or was it more because she smoked and was overweight; or was her doctor negligent in prescribing the pill to her when she was over 30 , smoked, and had a family history of stroke and high blood pressure. Doctors in Britain are afraid that if strict liability is introduced in Britain there will be endless scope for arguing over such questions and trying to "resolve the unresolvable."

The New Zealand case occurred in 1977. A 34-year-old woman, who had been taking oral contraceptives for about 12 years and had two children, was going on a deer-stalking trip. After discussion with her doctor it was decided that she should have an injection of Depo-Provera to cover her for the trip. Forty-eight hours after the injection she suffered a left-sided hemiplegia. The case was complicated by the local hospital diagnosing hysterical paralysis, but she was later transferred to a teaching hospital, where cerebral infarction was diagnosed.

A claim was made in 1978 on the grounds that: "She had suffered 'medical misadventure' in the form of a rare and grave disability which was the consequence of medical treatment properly administered (injection of Depo-Provera)." "Medical negligence" on the part of the local hospital was also claimed. The Accident Compensation Corporation took evidence from the neurosurgeon who treated the case, and he wrote: "I would think it most unlikely that the episode of cerebral infarction was related to the injection of Depo-Provera given 48 hours prior to the onset of symptoms." He also said in his letter, however, that he: "Was not an expert in the field of the effects of contraceptive therapy on blood coagulation disorders." Despite this qualification the Accident Compensation Corporation rejected the claim largely on his advice. An appeal was heard in 1979, and at the appeal the woman's husband turned up with a cutting from a local newspaper which suggested that the Department of Health in Wellington had further evidence on the dangers of DepoProvera. When he saw this cutting the judge referred the case back to the Accident Compensation Corporation. This case is still being investigated, which is not a good advertisement for the supposed rapidity of no-fault-systems. More than anything else, perhaps, this case illustrates how the New Zealanders are very much feeling their way with no-fault compensation for drug injuries.

\section{Unanswered questions}

Another interesting case was of a woman severely injured by practolol, which she had been taking both before and after April 1974, when no-fault compensation began. She had received compensation from the manufacturer but had later come to the Accident Compensation Corporation on the grounds that some of her disability had resulted from the drugs taken after April 1974. The Accident Compensation Corporation had accepted her claim but was faced with the impossible difficulty of deciding how much of her disability resulted from the drugs taken after
April 1974. One of the interesting aspects of this case is that there were probably $20-40$ people in New Zealand injured by practolol, and yet the Accident Compensation Corporation is dealing with only one or possibly two cases. Many drug-injured people just do not think of applying to the Accident Compensation Corporation. Is this not a failure of a no-fault system which has the explicit aim of making compensation more available than it was under the old system ? What would happen if many more people did lodge claims? What would happen if there were another series of cases like those injured by thalidomide tomorrow in New Zealand? Could the victims sue the manufacturer outside New Zealand (they certainly could not sue them in New Zealand)? In case such a problem arose should the Accident Compensation Corporation be able to sue the manufacturer?

There are many unanswered questions on how the Accident Compensation Corporation will deal with people injured by drugs. The rest of the world will watch with interest as it begins to answer them.

I thank all the members of the Accident Compensation Corporation who spoke to me; and Dr Arthur Coombes; Dr Brian Rhodes; Professor E G McQueen; Professor G S M Kellaway; Margaret Vennell; Professor T G Ison; and Geoffrey Palmer MP. None of these people, however, are likely to agree with everything that I have written.

\section{References}

${ }^{1}$ Smith R. Problems both sides of the Atlantic. Br Med 71981 ;282:1443-5. ${ }^{2}$ Smith R. Product liability all dressed up American style. Br Med 7 1981; 282:1535-7.

${ }^{3}$ Smith R. Two solutions to an insoluble problem. Br Med $\mathcal{F} 1981$;282: 1610-2.

${ }^{4}$ Royal Commission on Civil Liability and Compensation for Personal Injury. Report. London: HMSO, 1978. (Cmnd 7054). (Pearson Commission.)

${ }^{5}$ Anonymous. A neglected reform. The Times 1981;Aug 21:13 (col 1-3).

${ }^{6}$ Hill G. Easing the long hard road towards justice. The Times 1982; March $12: 10(\operatorname{col} 1-8)$

7 Anonymous. Compensation for drug injury. $B r$ Med $\mathcal{f} 1979$;ii:1674-5.

8 Anonymous. Product liability. $\mathrm{Br} \mathrm{Med} \mathcal{F} 1979 ; \mathrm{i}: 1663-4$.

9 Anonymous. Unwanted drug effects: whose responsibility ? Lancet 1979; ii $: 21$.

10 The Medicines Commission. Annual report for 1978. London: Department of Health and Social Security, 1979:18-9.

11 Anonymous. Medical misadventure. Medical Information Bulletin No 14. Wellington: ACC, 1981.

12 Vennell MA. Medical negligence and the effect of the New Zealand accident compensation scheme. Zeitschrift für Vergleichende Rechtswissenschaft $1981 ; 80: 227-40$.

13 (1977) 1 NZAR 130. November 1976 ACC Rep 58.

14 ACC Report 1978; July:44-9.

15 ACC Report 1979;March: 53.

An elderly patient cannot be relied on to take her thyroid tablets. How best may this problem be overcome?

If an old person cannot be relied on to take medicines then any medicine must be given under supervision by somebody else. Many old people have their tablets put out for them and take them under the eye of other members of their family, a neighbour, a visiting nurse, or even a home help. Thyroxin is very long acting and does not achieve its maximum effect for ten days. There is no necessity, therefore, for thyroxin to be given every day. A supervised administration of thyroxin tablets once or twice a week would be quite appropriate. I know of no publication describing this form of administration of thyroxin to old people, but once-weekly medication was reported as satisfactory in hypothyroid children who could not be relied on to take tablets successfully. ${ }^{1}$ An appropriate dose for an old person might be $0.3 \mathrm{mg}$ of thyroxin every third day or $0.7 \mathrm{mg}$ once a week. Serum concentrations of thyroxine and thyroid-stimulating hormone should be estimated periodically.-R E IRVINE, consultant physician, Hastings.

1 Sekadde CS, Slaunwhite WR, Aceto T, Marnay K. Administration of thyroxin once a week. $\mathcal{F}$ Clin Endocrinol Metab 1974;39:759-64. 